\title{
Evaluation of the Quality of Wood Pellets Available on the Market
}

\author{
Joanna Szyszlak-Bargłowicz ${ }^{1}$, Grzegorz Zając ${ }^{1, *}$, Małgorzata Hawrot-Paw ${ }^{2}$, and Adam Koniuszy ${ }^{2}$ \\ ${ }^{1}$ University of Life Sciences in Lublin, Department of Power Engineering and Transportation, Gleboka 28, 20-612 Lublin, Poland \\ ${ }^{2}$ West Pomeranian University of Technology, Department of Renewable Energy Sources Engineering, Papieża Pawła VI 1, 71 -459 \\ Szczecin, Poland
}

\begin{abstract}
The purpose of the research was to assess the quality of wood pellets available on the market. This assessment was made on the basis of the technical analysis and elemental composition: $\mathrm{C}, \mathrm{H}, \mathrm{N}, \mathrm{S}$. 14 different types of wood pellets available on the market were tested, each of them came from a different producer. In addition, an attempt was made to assess the content of organic matter in the tested pellets on the basis of methane fermentation. The innovation in the presented work is the use of biomethane production potential assessment for pellet fuel, which until now has been practised only in the case of substrates for biogas production. The parameters characterizing the tested pellets in energy terms did not differ significantly. The high calorific value and low ash and sulfur content indicated that the output biomass was of good quality. The differences in the production potential of biomethane of the tested pellets do not allow to state unequivocally that methane fermentation can be used to assess the quality of pellets and their contents of organic matter. However, the large BMP differences obtained for individual pellets suggest that some pellets may contain impurities inhibiting the fermentation process.
\end{abstract}

\section{Introduction}

Plant biomass is an attractive source of renewable energy. It is characterized by the widespread occurrence and availability, which boosts its popularity among agricultural producers and potential users of heat and electricity it can generate. Plant biomass, however, must be properly processed, because in its original state its density is low. Low density can increase the cost of storage, transport or exploitation of biomass. Therefore, there is a need to process it, e.g. by compaction to the form of pellets, which can be used in heating systems, individual heating installations, in fireplaces or boilers of single-family houses. Any type of solid biomass can be subjected to compaction. Biomass subjected to this process should not contain mechanical impurities such as stones, sand. Their occurrence in the raw material may negatively affect the operation of the production line as well as pellets quality [1]. The main raw material for pellets production is: wood waste - sawdust, shavings, vegetable waste - cereal, rapeseed as well as vegetable raw materials from agricultural crops - hay, straw [2].

The attractiveness of pellets as biofuels is determined by their characteristics such as low moisture, low ash and sulfur content, high calorific value as well as ease of storage, transport and distribution.
The introduction of the European quality standard for pellets EN14961 contributes to the harmonization of guidelines for the production of both wood pellets and pellets made from materials other than wood. By definition, this biofuel should not have harmful chemical substances, e.g. glues or varnishes, in its structure [3]. Nevertheless, pellet users have often encountered various types of impurities during operation, which impaired the quality and performance of the biofuel.

The purpose of the research was to assess the quality of wood pellets available on the market. This assessment was made on the basis of the determination of calorific value - LHV, moisture content - M, ash - A, volatile matter content $-\mathrm{V}$ and elemental composition: $\mathrm{C}, \mathrm{H}, \mathrm{N}$, S. 14 different types of wood pellets available on the market were tested, each of them came from a different producer. In addition, an attempt was made to assess the content of organic matter in the tested pellets on the basis of methane fermentation. The innovation in the presented work is the use of biomethane production potential assessment for pellet fuel, which until now has been practised only in the case of substrates for biogas production.

\footnotetext{
Corresponding author: grzegorz.zajac@up.lublin.pl
} 


\section{Methodology}

The subject of the study was the commercially available hardwood as well as coniferous wood pellets. The pellets were purchased from local distributors and DIY stores. 14 different types of this biofuel from different producers were tested. All the pellets met the requirements of the EN14961 standard in the AI class, certified by the manufacturer. Pellet manufacturers do not provide the exact type of biomass from which the pellets were made.

The LECO thermogravimetric analyzer TGA701 was used to determine the moisture accordance with the requirements of EN ISO 18134 and the ash content accordance with the requirements of EN ISO 18122. The carbon, hydrogen and nitrogen contents tests were carried out using the LECO CHN 682 analyzer. The contents of carbon, hydrogen and nitrogen in the dry biomass were determined by instrumental methods $(\mathrm{C}$ and $\mathrm{H}$ by the high-temperature combustion with IR detection, $\mathrm{N}$ by means of the katharometer method) according to EN-ISO 16948. The sulfur content was determined by the high-temperature combustion method with IR detection in accordance with EN-ISO 16994. The determinations were made in triplicate. The calorific value was determined using an automatic, isoperibolic LECO AC600 calorimeter, according to EN-ISO 1928. The result was the average of three measurements.

Research on the biomethane production potential was carried out using the Automatic Methane Production Potential Tester (AMPTS II) from Bioprocess Control Sweden AB. On-line measurements of small flows of biomethane formed during methane fermentation from a biodegradable substrate were carried out. The experiment was conducted under thermophilic methane fermentation $\left(55^{\circ} \mathrm{C}\right)$.

\section{Results of research}

The results of the technical-elementary analysis of the tested pellets are presented in Table 1 and 2.

Table 1. Results of the technical analysis of the tested pellets.

\begin{tabular}{|l|l|l|l|l|}
\hline Pellet & $\begin{array}{c}\text { Moisture } \\
\text { M } \\
{[\%]}\end{array}$ & $\begin{array}{c}\text { Ash } \\
\text { A } \\
{[\%]}\end{array}$ & $\begin{array}{c}\text { Volatile } \\
\text { V } \\
{[\%]}\end{array}$ & $\begin{array}{c}\text { LHV } \\
{\left[{\left.\mathrm{MJ} \cdot \mathrm{kg}^{-1}\right]}\right.}\end{array}$ \\
\hline P1 & 6.02 & 0.87 & 75.10 & 17.96 \\
\hline P2 & 6.33 & 0.45 & 78.04 & 18.31 \\
\hline P3 & 6.90 & 0.70 & 76.00 & 17.90 \\
\hline P4 & 7.37 & 1.03 & 75.72 & 17.23 \\
\hline P5 & 6.15 & 0.49 & 76.71 & 18.30 \\
\hline P6 & 7.65 & 0.81 & 75.46 & 17.86 \\
\hline P7 & 6.94 & 1.02 & 74.05 & 17.65 \\
\hline P8 & 6.27 & 0.36 & 77.03 & 17.18 \\
\hline P9 & 4.75 & 0.26 & 77.64 & 18.82 \\
\hline P10 & 6.80 & 0.39 & 76.66 & 18.46 \\
\hline P11 & 6.52 & 1.32 & 75.65 & 17.25 \\
\hline P12 & 3.91 & 0.47 & 77.31 & 18.84 \\
\hline P13 & 4.97 & 0.43 & 76.33 & 18.57 \\
\hline
\end{tabular}

\begin{tabular}{|l|l|l|l|l|}
\hline P14 & 4.17 & 0.88 & 75.95 & 17.78 \\
\hline
\end{tabular}

The LHV calorific value of the tested pellets was high and ranged from $17.18 \mathrm{MJ} \cdot \mathrm{kg}^{-1}$ for P8 pellets to $18.84 \mathrm{MJ} \cdot \mathrm{kg}^{-1}$ for P12 pellets, which defined them as attractive renewable fuels. The moisture content of $\mathrm{M}$ was from $3.91 \%$ in $\mathrm{P} 12$ pellets to $7.65 \%$ in $\mathrm{P} 6$ pellets. On the other hand, ash A content in all the tested pellets was low and ranged from $0.26 \%$ to $1.32 \%$. The carbon content $\mathrm{C}$ was from $47.21 \%$ in $\mathrm{P} 14$ pellets to $49.92 \%$ in $\mathrm{P} 8$ pellets. The hydrogen $\mathrm{H}$ content was from $5.61 \%$ in $\mathrm{P} 11$ pellets to $5.84 \%$ in $\mathrm{P} 8$ pellets. The nitrogen $\mathrm{N}$ content was varied and ranged from $0.021 \%$ in $\mathrm{P} 13$ pellets to $1.77 \%$ in $\mathrm{P} 4$ pellets. The sulfur $\mathrm{S}$ content ranged from $0 \%$ in $\mathrm{P} 13$ pellets to $0.011 \%$ in $\mathrm{P} 2, \mathrm{P} 5, \mathrm{P} 11$ pellets. In addition, most of the tested pellets met the requirements of the EN-14961 standard for pellets of the AI or AII category, apart from the P4 and P12 pellets in which an excessive nitrogen content was found (Table 3).

Table 2. Results of the elemental analysis of the tested pellets.

\begin{tabular}{|l|l|l|l|l|}
\hline Pellet & $\begin{array}{c}\text { Carbon } \\
\mathrm{C} \\
{[\%]}\end{array}$ & $\begin{array}{c}\text { Hydrogen } \\
\mathrm{H} \\
{[\%]}\end{array}$ & $\begin{array}{c}\text { Nitrogen } \\
\mathrm{N} \\
{[\%]}\end{array}$ & $\begin{array}{c}\text { Sulfur } \\
\text { S } \\
{[\%]}\end{array}$ \\
\hline P1 & 48.79 & 5.70 & 0.17 & 0.006 \\
\hline P2 & 47.77 & 5.67 & 0.12 & 0.011 \\
\hline P3 & 48.27 & 5.72 & $0 ., 08$ & 0.003 \\
\hline P4 & 47.85 & 5.68 & 1.77 & 0.001 \\
\hline P5 & 48.64 & 5.78 & 0.06 & 0.011 \\
\hline P6 & 49.07 & 5.78 & 0.12 & 0.005 \\
\hline P7 & 49.58 & 5.76 & 0.22 & 0.004 \\
\hline P8 & 49.92 & 5.84 & 0.15 & 0.008 \\
\hline P9 & 48.06 & 5.62 & 0.26 & 0.009 \\
\hline P10 & 48.51 & 5.69 & 0.07 & 0.005 \\
\hline P11 & 48.51 & 5.61 & 0.05 & 0.011 \\
\hline P12 & 47.64 & 5.75 & 1.35 & 0.010 \\
\hline P13 & 47.78 & 5.74 & 0.02 & 0.000 \\
\hline P14 & 47.21 & 5.70 & 0.08 & 0.006 \\
\hline
\end{tabular}

Table 3. Specification of wood pellets for non-industrial applications [EN-14961].

\begin{tabular}{|l|c|c|c|}
\hline Parametr & AI & AII & B \\
\hline LHV [MJ·kg ${ }^{-1}$ ] & $16.5-19$ & $16.3-19$ & $16-19$ \\
\hline Ash A [\%] & $<0.7$ & $<1.5$ & $<3$ \\
\hline Moisture M [\%] & $<10$ & $<10$ & $<10$ \\
\hline Nitrogen N [\%] & $<0.3$ & $<0.5$ & $<1 \%$ \\
\hline Sulfur S [\%] & $<0.03$ & $<0.03$ & $<0.04$ \\
\hline
\end{tabular}

The presented results of estimations of the energy parameters of the tested pellets are confirmed by the previous authors' works [4-6]. The calorific value of pellets from various types of wood biomass reported in the work [7] was from 17.40 to $19.42 \mathrm{MJ} \cdot \mathrm{kg}^{-1}$, with a few percent moisture (4.7-7.3\%) and quite diverse ash content (0.33-3.71\%). According to the study [8], which is a review of literature reports on the chemical composition of biomass, the content of volatile parts $\mathrm{V}$ 
in various types of wood biomass was $69.5-86.3 \%$, and the contents of $\mathrm{C}, \mathrm{H}, \mathrm{N}$ and $\mathrm{S}$ were quite diverse, namely: C 48.7-57\%; H, 5.4-10.2\%; N 0.1-07\%; S 0.01$0.42 \%$.

The pellet standard EN 14961-1 does not provide for testing for organic matter content. This information can be obtained by analyzing the ash content. However, when waste wood pellets are introduced, the ash content will not show this type of practice. An auxiliary function can be fulfilled by the test consisting in assessing the efficiency of methane production because only organic matter will be fermented and the components such as paints, resins and glues may negatively affect the fermentation process. In order to confirm the organic matter content in the tested pellets, their methane fermentation was carried out. The results of research on the biomethane production potential during thermophilic fermentation are shown in Fig. 1.

The results of research on the biomethane production potential of the tested pellets during thermophilic fermentation were very diverse.

The highest production potential of biomethane during methane fermentation was found for P14 and P7 pellets, $150.66 \mathrm{Nml}^{\circ} \mathrm{gVS}^{-1}$ and $139.62 \mathrm{Nml}^{\circ} \cdot \mathrm{gVS}^{-1}$, respectively, which may indicate the highest content of organic matter and their best quality. The lowest biomethane production potential during methane fermentation was found for P12 and P4 pellets, 8.82 $\mathrm{Nml} \cdot \mathrm{gVS}^{-1}$ and $14.10 \mathrm{Nml} \cdot \mathrm{gVS}^{-1}$, respectively, which may indicate the presence of impurities (paints, resins, waste wood adhesives), which may have impeded anaerobic degradation. It is worth noting that these pellets were characterized by a higher nitrogen content $(<1 \%)$. In addition, low biomethane production potential of about $20 \mathrm{Nml}_{\mathrm{gVS}}{ }^{-1}$ was found for P3, P5 and P13 pellets.

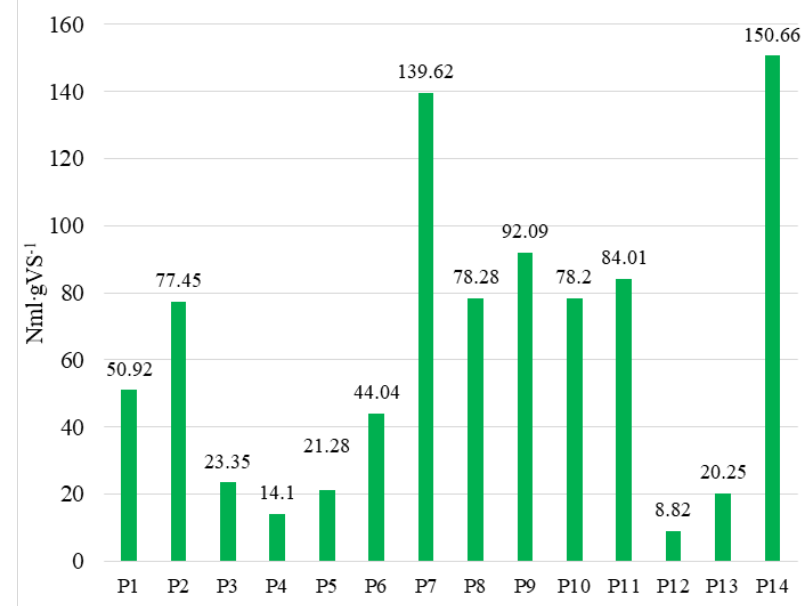

Fig. 1. Biomethane Production Potential BMP.

The results of the research on the biomethane production potential were not reflected in the results of the technical analysis. The pellets with the highest biomethane production potential included both the ones with low and the ones with high ash content, suggesting the presence of mineral compounds. Also, no relationship was found between the production potential of biomethane and the content of volatile compounds, which could indicate the presence of light compounds such as resins, paints and varnishes. The reference of the elemental analysis test results $(\mathrm{C} / \mathrm{N}$ ratio $)$ to the biomethane production potential does not suggest a relationship between them either - apart from the abovementioned $\mathrm{P} 4$ and $\mathrm{P} 12$ pellets.

Dostępne w literaturze wyniki badań [9] confirm the possibilities of methane fermentation of lignocellulosic biomass. A much higher final methane efficiency than obtained in the tests $\left(>250 \mathrm{ml} \cdot 1 \mathrm{~g}^{-1} \mathrm{VS}\right)$ was found for more than half of the 32 types of wood biomass tested, and some Salix willow clones were characterized by very high efficiency (300 $\left.\mathrm{ml} \cdot 1 \mathrm{~g}^{-1} \mathrm{VS}\right)$. In addition, attention was drawn to the interesting fact that conducting BMP tests for less than 50 days may not give the highest methane efficiency due to the duration of the initial phase of metaneogenesis.

In [10] a higher than obtained in the research, maximum methane efficiency was found at the level of $215 \mathrm{ml}$ from $1 \mathrm{~g}$ of bamboo biomass pretreated by the influence of high temperature and pressure. Methane could not be obtained from raw bamboo. At the same time, a negative correlation was found between the lignin content and the amount of methane produced.

It should be noted that the presented research results are the only study on methane fermentation of wood pellets. Therefore, it is difficult to compare the results of research on the biomethane production potential of the tested pellets with the available literature.

It should be remembered that the quality of the pellets is important and directly affects the way they are used as solid biofuels. The basic problems related to the quality of combusted pellets and the potential low quality causes are $[11,12]$ :

1. Excessive ash and slag formation:

- presence of bark, seeds or other types of biomass with a higher ash content than pure wood;

- presence of unwanted additives such as dirt or sand;

- presence of other types of waste.

2. Sediments and corrosion:

- presence of biomass other than pure wood;

- presence of other materials with a high content of volatile compounds such as sulfur and chlorine compounds.

3. Poor combustion and blockage of the fuel supply system:

- too high ash content;
- too high moisture content. 
Nocoń et al. [13], by making petrographic characteristics of commercially available wood pellets, found in the analyzed samples unacceptable organic inclusions such as: fossil coals and their derivatives as well as polymer materials of natural origin. Inorganic inclusions which are not allowed and marked in the tested pellets are: rust, metal pieces, plastics and polymeric materials of inorganic origin.

\section{Main conclusions}

Quality control of the produced pellets is aimed at establishing the performance standards and quality of pellets, taking into account critical values for pollution and energy values. Keeping limit parameters for, among others, diameter, durability, density, dust content, ash, humidity, calorific value as well as the content of individual chemical elements, provides the basis for the criteria for controlling the purchased product and defining the requirements from the manufacturer regarding the fulfillment of specific fuel parameters at delivery. Even pellets that are subject to certification may contain unacceptable impurities in the form of metals or plastics [13].

The parameters characterizing the tested pellets in energy terms did not differ significantly. The high calorific value and low ash and sulfur content indicated that the output biomass was of good quality.

The highest production potential of biomethane during thermophilic methane fermentation was found for P14 and P7 pellets, which may indicate the highest organic matter content and the best quality.

The lowest production potential of biomethane during thermophilic methane fermentation was found for P4 and P12 pellets, possibly suggesting the content of impurities in them which may have hindered anaerobic fermentation, which may indicate the low quality of these pellets.

The differences in the production potential of biomethane of the tested pellets do not allow to state unequivocally that methane fermentation can be used to assess the quality of pellets and their contents of organic matter. However, the large BMP differences obtained for individual pellets suggest that some pellets may contain impurities inhibiting the methane fermentation process. These impurities can affect the emission of toxic exhaust components when burning pellets as well as contribute to corrosion and wear of boiler components. This requires further verification tests. The authors plan to extend the research on the production potential of wood pellets biomethane during mesophilic and thermophilic fermentation, taking into account the longer time of conducting the experiment (50 days), which will allow a verification of the research results obtained so far. It will also allow looking for a correlation between the ash and volatile matter contents and BMP results.

\section{Acknowledgements}

Publication is funded by the Polish National Agency for Academic Exchange under the International Academic Partnerships Programme from the project „Organization of the 9th International Scientific and Technical Conference entitled Environmental Engineering, Photogrammetry, Geoinformatics - Modern Technologies and Development Perspectives".

\section{References}

1. M. Jakubiak and W. Kordylewski, Arch. Spalania 8, 108 (2008)

2. I. Niedziółka and M. Szpryngiel, Agric. Eng. 136, 267 (2012)

3. R. Hejft and S. Obidziński, J. Res. Appl. Agric. Eng. 57, 63 (2012)

4. J. Szyszlak-Bargłowicz, Agric. Eng. 19, 121 (2015)

5. J. Szyszlak-Barglowicz, G. Zajac, and T. Slowik, Rocz. Ochr. Srodowiska 19, 715 (2017)

6. G. Zajac, J. Szyszlak, J. Wasilewski, and A. Kuranc, Fresenius Environ. Bull. 26, 4663 (2017)

7. J. I. Arranz, M. T. Miranda, I. Montero, F. J. Sepúlveda, and C. V. Rojas, Fuel 142, 199 (2015)

8. S. V. Vassilev, D. Baxter, L. K. Andersen, and C. G. Vassileva, Fuel 89, 913 (2010)

9. C. E. Turick, M. W. Peck, D. P. Chynoweth, D. E. Jerger, E. H. White, L. Zsuffa, and W. A. Kenney, Bioresour. Technol. 37, 141 (1991)

10. F. Kobayashi, H. Take, C. Asada, and Y. Nakamura, J. Biosci. Bioeng. 97, 426 (2004)

11. M. Hawrot-Paw, A. Zmuda, and A. Koniuszy, Przem. Chem. 98, (2019)

12. G. Zając, J. Szyszlak-Bargłowicz, A. Dudziak, A. Kuranc, and J. Wasilewski, in IX Int. Sci. Symp. Farm Mach. Process. Manag. Sustain. Agric. Symp. Proc. (2017)

13. A. Nocoń, I. Jelonek, M. Jach-Nocoń, and Z. Jelonek, Bull. Miner. Energy Econ. Res. Inst. Pol. Acad. Sci. 104, 131 (2018) 